\title{
A psicanálise em um Batalhão de Polícia Militar: algumas reflexões acerca de um trabalho de pesquisa em psicanálise
}

\author{
Psychoanalysis in a Military Police Battalion: a few reflections about a research action in psychoa- \\ nálisis
}

Fernanda Cabral Samico.

Como citar esse artigo. Samico FC. A psicanálise em um Batalhão de Polícia Militar: algumas reflexões acerca de um trabalho de pesquisa em psicanálise. Revista Mosaico. 2014 Jul./Dez.; 05 (2): 05-09.

\begin{abstract}
Resumo
Este trabalho visa pensar a clínica psicanalítica, suas possibilidades e limites em um campo tão particular como o do $10^{\circ}$ Batalhão de Polícia Militar do Estado do Rio de Janeiro (10 ${ }^{\circ}$ BPMRJ). Nossa atuação neste espaço parte da aposta que, ao possibilitarmos a entrada da psicanálise e sua atuação na contramão do apagamento subjetivo que a identificação com a farda promove, permitimos que nós atuemos como promotores de implicações subjetivas e possibilitamos o surgimento de um campo onde os afetos possam ser acolhidos. Faz-se necessário reconhecer a importância da prática da psicanálise em um contexto cuja imposição de uma obediência sem questionamento, aliada à sobrecarga de trabalho e situações de risco e estresse, leva ao adoecimento e à passagens ao ato de grande gravidade. A aposta ética no sujeito do inconsciente e na psicanálise como dispositivo são os pontos norteadores de nossa atuação. É preciso, portanto, pensar a criação de uma prática construída a partir da especificidade de um campo como o $10^{\circ}$ BPMRJ, para que, a partir da aplicação da psicanálise e seu dispositivo, possa-se acolher e fazer falar o próprio de cada um em detrimento do adoecimento que a identificação com a farda promove em alguns policiais. Palavras-Chave: Psicanálise. Ética. Polícia.
\end{abstract}

\begin{abstract}
This work aims to think the psychoanalytic clinic, its possibilities and limits in a particular field such as the 10th Battalion of the Military Police of Rio de Janeiro (10 ${ }^{\circ}$ BMPRJ). Our work in this field. bids that by allowing psychoanalysis and its performance to act against the sibjective deletion that the identification with the uniform promotes, it is possible to act as promoters of subjective implications and we enable the emergence of a field where the affections can be heard and considered as accepted. It is necessary to recognize the importance of psychoanalysis as a practice in a context whose the habit of imposing an obedience without question, together with the increased workload and risk, aditioned with work stress, leads to illness and "passages to the act" of great gravity. Our compass is the Ethics in psychoanalisis, that always bet on the subject of the unconscious, also works as a device and points the guidance of our work. We must therefore think about the creation of a practice built from the specificity of a field as the 10th BMPRJ so that, from the application of psychoanalysis and its device, one can harbor and make-speak each own at the expense of illness that identification with the uniform promotes in some policemen. Keywords: Psychoanalisis. Ethics. Police.
\end{abstract}

\section{A psicanálise em um Batalhão de Polícia Militar: algumas reflexões acerca de um trabalho de pesquisa em psicanálise}

Este trabalho é um exercício reflexivo sobre a clínica psicanalítica, suas possibilidades e limites a partir da atuação em um campo muito particular: o de um Batalhão de Polícia Militar. Freud já apontava para o futuro da psicanálise e sua aplicabilidade fora das paredes do setting analítico, seu campo original de atuação. E uma chance de estar em um campo tão peculiar como este, para realizar um trabalho clínico calcado na ética da psicanálise, não poderia ser ignorada. O convite veio por meio do curso de Psicologia da Universidade Severino Sombra, a partir da chance de supervisionar a atuação de estagiários de psicologia no $10^{\circ}$ Batalhão de Polícia Militar do Estado do Rio de Janeiro ( $10^{\circ}$ BPMRJ), bem como de conduzir uma pesquisa fundamentada nessa atuação.

Primeiro de tudo é preciso pontuar a riqueza do encontro da psicanálise com a universidade e a miríade de possibilidades que esta articulação possibilita, especialmente do ponto de vista da atuação do aluno. Nós permitimos que o aluno experimente o hiato entre saber e verdade, entre a produção científica produzida pela academia e a produção subjetiva produzida pelo inconsciente. E conseguimos demarcar um espaço onde seja possível o engajamento do aluno no que é mais caro à psicanálise: "a questão do que pode determinar o sujeito, o que pode causá-lo, produzi-lo, fazê-lo emergir" (MAURANO, 2006, p. 215). Além de possibilitarmos a 
experiência de uma "transmissão de um saber que não se sabe, ou seja, a transmissão de um enigma, um dizer pela metade, que é fisgado pela verdade, mas que não elide o abismo que há entre esta e o saber" (MAURANO, 2006, p. 222).

E foi pelo caminho do contingencial que começamos o trabalho de pesquisa e estágio com os policiais do $10^{\circ}$ Batalhão. É notório que a inserção da psicanálise em instituições é sempre atribulada (ALTOÉ, 2005). Em uma instituição de organização militar, como o $10^{\circ} \mathrm{BPMRJ}$, com tudo que representa ou estabelece em termos de laços sociais e estrutura, o desafio é ainda maior, exatamente pela proposta psicanalítica de subversão do modelo imposto pelo regime militar. A polícia do Rio de Janeiro está, desde sua criação, abalizada no modelo militar de organização e, portanto, compartilha com as Forças Armadas categorias organizacionais como batalhões, companhias, patentes, fardas, além de todo tipo de regras e interdições que marcam o trânsito nos espaços, o fluxo do tempo e das relações. Seu hino tem um refrão muito curioso: "Ser Policial é, sobretudo, uma razão de ser / É enfrentar a morte, mostrar-se um forte no que acontecer" (ALBERNAZ apud MUNIZ, 1999: 166). Podemos analisar essa estrofe a partir de dois pontos: ser policial é uma razão de ser; e ser policial é enfrentar a morte e mostrar-se forte. Percebemos, portanto, duas indicações de vias identificatórias. A primeira com a própria existência do policial, que passa a denominar-se a partir da identidade policial. A segunda com uma posição invencível, capaz de ser forte inclusive ao enfrentar o que há de mais traumático para o ser humano, a morte. Em nossa atuação no Batalhão, foi fundamental entendermos que o que estava em jogo, em muitos comportamentos resistentes que encontramos, era o medo da queda dessa dupla identificação que muitos sujeitos dentro do Batalhão fazem maciçamente com o policial que nada teme, nada sofre e nada é, a não ser policial (MAZZA, MENEZES e SAMICO, 2013).

A identificação enquanto conceito recebeu de Freud algumas definições no decorrer do desenvolvimento da teoria psicanalítica. Mas em todas elas entende-se que, para haver identificação, é preciso que haja uma apropriação pelo sujeito de traços ou elementos de outro indivíduo, por ele eleito. Nas últimas formulações teóricas do termo, em 1921 e 1925, Freud liga o processo de identificação à eleição de alguém à posição de ideal do eu e ao surgimento do supereu, na saída do complexo de Édipo (ROUDINESCO e PLON, 1998).

No que toca à questão dos grupos, Freud defende que, diferentemente dos grupos efêmeros, nos grupos artificiais os indivíduos renunciam ao seu ideal do eu em prol do ideal do grupo, representado pelo líder. No grupo, então, são constituídos laços de identificação entre seus membros a partir do líder. Lembremos que este também é o mecanismo da hipnose e do enamoramento: o objeto amado é colocado no lugar do ideal do eu (FREUD, 1921/1996). E para Freud a identificação é a forma de amor mais arcaica.

A partir do mecanismo da identificação, podemos afirmar que a corporação policial militar, representada pelo chefe, toma o lugar de um pai onipresente, cujas ações são justificadas e executadas por seus membros a partir do amor que sentem pelo ideal que a polícia representa: ser policial é razão de ser. A imagem do policial, com sua farda e postura invencível é reforçada aos "praças" a cada treinamento de "rigorosa pedagogia militar de introjeção do ethos corporativo. O empenho exaustivo com a imagem institucional está [...] voltado para produzir [...] uma visão virtuosa e austera da organização policial militar" (MUNIZ, 1999:93). Qualquer manifestação de afetos que contradiga o ideal do policial forte coloca em risco o bom funcionamento da corporação, porque denuncia uma possibilidade de dissolução do grupo, já que aponta para uma vacilação de tal imagem.

Eric Laurent, em seu texto "Sete problemas de lógica coletiva na experiência da psicanálise segundo o ensinamento de Lacan" (2000), lembra que Freud se utilizou da hipnose para exemplificar o laço do objeto com o traço significante. Ou seja, é na hipnose que se condensa o ponto do significante ideal onde se marca o sujeito como $a$. Ainda nesse trabalho, Laurent elucida que Lacan, ao retomar a relação freudiana entre o grupo e o líder, também articulou a relação do grupo com das Ding, a Outra Coisa. Quando consideramos os grupos, argumenta Laurent, é preciso ter em conta os afetos presentes nas organizações coletivas: revolta, tédio, desejo, pânico. Lacan ponderou sobre a angústia pânico, que Freud localizava como efeito da desagregação do grupo, que ela revela, através do ódio e da agressividade, a pulsão de morte no que resta da operação de identificação com o Outro.

O resultado disso é que alguns policiais tão fortemente identificados com a farda, ícone da corporação, quando passam por situações de intensa pressão psicológica e estresse, recorrem à negação dos afetos. Estes afetos negados não deixam de existir e, portanto, de afetar, muitas vezes gravemente, a saúde mental e física dos policiais, assim como suas relações familiares, sociais e profissionais. Isso se exemplifica em alguns fenômenos clínicos muito comuns nos policiais com quem mantivemos contato: insônias sem motivos aparentes, crises de angústia recorrentes e passagens ao ato de grande gravidade, como impulsos suicidas e homicidas (ALVES e SAMICO, 2013). A angústia escapa do escudo que é a farda e marca sua presença.

A angústia é um afeto que interessa muito à psicanálise. Um “sinal” (LACAN, 1962-63/2004) daquilo que o sujeito evita e que define a sua verdade com relação ao seu desejo. Um afeto que não engana na direção da cura em psicanálise. Isto nos leva a nossa 
problemática: como pensar, então, em trabalhar com um afeto dessa ordem em um campo com as particularidades de um batalhão de polícia e cujos sujeitos, afetados pela angústia, passam ao ato por não terem como falar dos seus afetos?

Era preciso, portanto, possibilitar a criação de uma prática construída a partir das especificidades de um campo institucional como o $10^{\circ}$ BPMRJ. Nossa primeira frente de atuação foi disponibilizar uma agenda e uma escala com os horários que os estagiários estariam à disposição para marcação de consultas. Em contrapartida, o Batalhão nos forneceu uma sala e divulgou aos policiais o serviço que ofereceríamos. Esta estratégia não funcionou e durante algumas semanas nenhum atendimento foi marcado. Os estagiários, ociosos, começaram a circular no espaço do Batalhão, interagindo com os policiais que freqüentavam os pátios, cafeterias e estacionamentos. O resultado disso foi uma reação negativa por conta dos próprios policiais, que no princípio não aderiram à proposta e reagiram à presença dos estagiários com brincadeiras, piadas e chistes.

Sabemos a atenção que a psicanálise tem com o humor e principalmente com o chiste, formalizando-o como uma formação do inconsciente, ao lado dos sonhos e atos falhos. Portanto, entendemos as piadas como indicadores quenos apontavam paraum fenômeno clínico bastante conhecido: a resistência. Freud nos ensina que resistências são passíveis de interpretação. São dados clínicos porque são indicadores do que estaria recalcado (ROUDINESCO, 1998). Entendemos que os policiais estavam reagindo a algo que os movia profundamente: a possibilidade de ter um espaço - dentro da instituição que muitas vezes associam como causadora de sofrimento para falarem livremente sobre suas angústias e dores. A manobra que adotamos foi fundamental: resolvemos, então, não nos defendermos das piadas e nem nos recuarmos dos espaços de convivência. Decidimos utilizar esses momentos de descontração nos espaços de circulação como momentos de causação de saber.

Foi pela escolha do caminho chistoso dos trocadilhos e brincadeiras entre os policiais e estagiários que percebemos uma mudança no laço entre os mesmos. Os policiais passaram a receber os estagiários com mais carinho e alegria. Mas ainda assim a adesão ao atendimento individual não acontecia. Nas reuniões de pesquisa e supervisões nos perguntávamos por que não havia adesão às sessões individuais. Lembramos que Lacan ([1954-1955], 1997) situa a resistência do lado do analista: aquilo que o analista não consegue escutar e manejar está diretamente relacionado com os pontos não analisados em sua própria análise pessoal. É a função do desejo do analista que atua como antídoto, porque não procura as identificações criadas pela fantasia, mas funcionar como semblante, para fazer-se o ponto de apoio para que a falta de objeto esteja em função.

Percebemos como estávamos idealizando nossa proposta de atendimento clínico como única possibilidade de atuação no Batalhão. Mas, mais complicado ainda, enxergamos como estávamos nos posicionando narcisicamente como únicos portadores da solução para os males daquele grupo: a psicanálise os salvaria da dor, do adoecimento e da alienação ao sistema. Ledo engano! Começamos, então, a nos descolar do modelo clínico idealizado e começamos a debater sobre a possibilidade de estarmos no espaço do Batalhão, não como portadores de uma técnica terapêutica, mas de uma exigência ética. Passamos a estudar sobre a psicanálise aplicada e sobre o dispositivo psicanalítico nas instituições. Abandonamos a tão idealizada paixão de curar e começamos a por em ação uma prática voltada para a escuta do mal-estar: passamos a simplesmente escutar o mal-estar na cantina, no pátio, onde ele pudesse ser anunciado. Abandonamos o "tratamento" e apostamos na "experiência" psicanalítica. E nós, sem furor sanandis (FREUD, 1912/1996), pudemos finalmente encarnar uma "certa presença, que permite que a operação analítica aconteça, de maneira pura e/ou aplicada" (MATTOS, 2003, p. 20).

Com isso, também foi preciso aceitar e acolher o mal-estar que um modelo de intervenção tão solto causou no nosso próprio grupo de estágio e pesquisa. Muitos alunos o abandonaram e migraram para outros campos de estágio mais amarrados e sistematizados. Os que conosco permaneceram, suportaram brilhantemente o mal-estar e puderam participar do nascimento de uma estratégia de atuação em psicanálise, calcada no acolhimento do real enquanto contingência e no desejo de produzir a mais pura diferença.

Tiramos como lição, em nossas incursões no $10^{\circ}$ BPMRJ, que há pouco espaço para a palavra livre. Falar com outros não é ação corriqueira dentro de um batalhão porque a palavra está sempre submetida à hierarquia. "De certa maneira, a palavra costuma ser acionada como uma instância reativa, isto é, como um expediente de emissão tão-somente de respostas, seja na interação com os oficiais superiores, seja no contato com o cidadão" (MUNIZ, 1999: 90). Vemos em nossa cultura o espelho disso quando os quadros de humor representam o policial, sempre como um personagem abobalhado que responde palavras simples e diretas como "positivo" e "operante" quando solicitado. Ora, Lacan é bem preciso quando afirma em "Função e Campo da Fala e da Linguagem em Psicanálise" (1953/1998) que a psicanálise dispõe de uma via exclusiva de trabalho: a fala do paciente. É com a fala que trabalhamos e é a fala plena, a partir do que ela convoca nos afetos, que produz efeitos. Dar nome ao que está no campo do inominável, fazer barra ao real do gozo são funções primordiais da fala. Nesse sentido, o dispositivo acionado pela experiência psicanalítica se situa no oposto desse contexto policial militar em que o poder hierárquico predomina e organiza as relações humanas. A relação analítica é baseada no fato de que o 
poder que o analista detém, a partir da transferência que lhe é dirigida pelo analisando, não será utilizado pelo analista (MILLER, 2009:181).

Convidar os sujeitos que nos procuram no Batalhão a falar é acolher seu discurso e introduzir uma possibilidade de articulação entre sujeito e castração, entre Simbólico e Real, entre o objeto e das Ding. A psicanálise possibilita a existência de um campo onde a palavra pode ser ouvida a partir de uma posição ocupada pelo analista que exclui a normatização do discurso (RINALDI, 1996). A ética da psicanálise está centrada no bem-dizer o próprio sintoma, e tem como direção, desde os primeiros textos psicanalíticos freudianos, trazer o que é da ordem do sofrimento para o regime da palavra. Lacan nos ensina, em seu Seminário sobre a Ética (1959-60/1997), que a ética psicanalítica se liga ao que está além do princípio de prazer, além do recalque: vai da questão do desejo, à relação com o falo, à localização do homem em relação ao Real, e à ficção do desejo na fantasia. A fantasia nos é outorgada pelo Outro para que possamos fazer face ao real e sua ação promove um afunilamento, uma parcialização "desse gozo ilimitado que invadia todo o corpo, com a consequente redução de seu gradiente mortífero [... ]" (JORGE, 2010: 142). A fantasia é o que nos protege das invasões devastadoras do real porque sua tessitura simbólico-imaginária funciona como uma tela protetora, que possibilita o contato com o mundo à nossa volta $\mathrm{e}$ promove os laços sociais.

Aqui tocamos no cerne de nossa questão. De que forma construir um espaço de prática psicanalítica em uma instituição militar - com todas as suas marcas institucionais e a incidência adoecedora em seus sujeitos - e possibilitar a ação necessária para garantir que essa prática seja calcada na ética psicanalítica? Diante desse desafio, é necessário ter em mente que qualquer dispositivo, para que seja nomeado psicanalítico, deve operar sem a mediação de um saber prévio e "operar a partir de um furo no saber, o que implica na sustentação de um real, único capaz de dar lugar ao inconsciente" (ELIA, 2005, p. 117). Essa é a posição do analista, esteja ele na instituição ou em seu consultório particular.

Diante disto, estamos orgulhosamente sempre em franco caráter experimental em nosso trabalho no Batalhão! E a partir do momento que pudemos ser capazes de acolher esta posição, para nossa grande surpresa, a adesão ao atendimento individual começou a aumentar. Já nos disponibilizaram diversas salas para atendimento individual e contamos com um número crescente de estudantes interessados em nosso trabalho. Aprendemos que, assim como na clínica, nossa prática na instituição é e sempre será contingencial. Devemos nos manter sensíveis para o sujeito e suas singularidades, acolhendo a impossibilidade de previsão de resultados. Nossas regras são congruentes ao real que insiste em imprimir seus efeitos em qualquer montagem da cultura do ser falante. Este foi nosso grande aprendizado: acolher a impossibilidade de previsão que toda atuação com o real traz.

E finalizamos nossa fala com a certeza de que “[...] a estratégia e a tática da psicanálise aplicada não propõe soluções gerais; cada um responde como pode e como quer, não há fórmula para um final feliz, nem para o bem-estar, no entanto existe uma política, a política do bem dizer, que uma vez alcançada, produz efeitos no mal-estar, com resultados tanto para aquele que encontrou esse bem quanto para a comunidade (HOLCK, 2008, p. 24). Cabe então, pensar em uma direção de tratamento preocupada acima de tudo com a indicação ética de causar a mais pura diferença a partir da não elisão do real e do acolhimento do que é próprio do ser falante e sua condição desamparada frente à linguagem, ao desejo e ao gozo.

\section{Referências}

ELIA, Luciano e SANTOS, Kátia Wainstock A. Bem-dizer uma experiência. In: ALTOÉ, Sônia e LIMA, Marcia Mello de. (Orgs.) Psicanálise, Clínica e Instituição. Rio de Janeiro: Rios Ambiciosos, 2005, p. 107-128.

FLORENCE, Jean. L'identification dans la théorie freudienne. Bruxelles Facultés universitaires Saint-Louis, 1984

FREUD, Sigmund. Psicología de las masas y analisis del yo (1921). In Obras Completas Sigmund Freud. Buenos Aires; Amorrortu Ed. 1992. p. 63-136

FREUD, Sigmund. Recomendação aos médicos que exercem a psicanálise [1912]. In Edição Standard das Obras Psicológicas Completas de Sigmund Freud. Rio de Janeiro: Imago, 1996. v. 12, p. 125-133.

JORGE, Marco Antônio Coutinho. Discurso e liame social: apontamentos sobre a teoria lacaniana dos quatro discursos. In: RINALDI, Dóris e JORGE, Marco Antônio Coutinho (Orgs.) Saber, verdade e gozo: leituras de o seminário, livro 17 de Jacques Lacan. Rio de janeiro: Rios Ambiciosos, 2002. p. $17-32$

.Fundamentos da psicanálise de Freud a Lacan: as bases conceituais. Rio de Janeiro: J. Zahar, 2005

Fundamentos da psicanálise de Freud a Lacan: a clínica da fantasia Rio de Janeiro: Zahar, 2010

LACAN, Jacques. Função e campo da fala e da linguagem em psicanálise. In Escritos. Rio de Janeiro: Zahar, 1988, p. 238-324

A direção do tratamento e os princípios de seu poder. In Escritos. Rio de Janeiro: Zahar, 1988, p. 591-652

Subversão do sujeito e dialética do desejo no inconsciente freudiano. In Escritos. Rio de Janeiro: Zahar, 1988, p 807-842

O seminário, livro 7: A Ética da Psicanálise (1959-60). Rio de Janeiro: Zahar, 1997.

O seminário, livro 9: A identificação, mimeo, inédito.

O seminário, livro 10: A angústia. Rio de Janeiro: Zahar, 1992.

LAURENT, Eric. "Sete problemas de lógica coletiva na experiência da psicanálise segundo o ensinamento de Lacan", In Opção lacaniana - Revista Brasileira Internacional de Psicanálise. n. 26/27. São Paulo. Edições Eólia, abr / 2000, p. 17-34

\section{Psicoanálisis y salud metal. Tres haches, Buenos Aires. 2000}

LEITE, Sônia. Angústia. Rio de Janeiro: Zahar, 2011

MAURANO, Denise. Um estranho no ninho ou a psicanálise na universidade. 
In Jorge, M. A. C. (Org.) Lacan e a formação do psicanalista. Rio de Janeiro: Contracapa, 2006, p. 209-227.

MATTOS, Sérgio. de A disponibilidade do analista. Correio: revista da Escola Brasileira de Psicanálise, n. 42, p. 19-26, 2003

MAZZA, Melissa da Silva, MENEZES, Thais de Souza e SAMICO, Fernanda Cabral. Resistência e transferência: o relato de uma experiência em um batalhão de polícia militar. 2013. Trabalho apresentado ao VII Congresso Nacional de Psicanálise da Universidade Federal do Ceará. Fortaleza, 2013.

MILLER, Jacques-Alain. "Puntuaciones sobre 'La dirección de la cura"" (1992). In: Conferencias porteñas, tomo 2. Buenos Aires: Paidós, 2009.

MUNIZ, Jacqueline. Ser Policial é, sobretudo, uma Razão de Ser. Cultura e Cotidiano da Polícia Militar do Estado do Rio de Janeiro. 286f. Tese (Doutorado em Ciência Política) Rio de Janeiro, Universidade do Estado do Rio de Janeiro, 1999.

RINALDI, Dóris. A ética da diferença: um debate entre psicanálise e antropologia. Rio de Janeiro, Ed. Jorge Zahar, 1996.

ROUDINESCO, Elizabeth. \& PLON, Michel. Dicionário de Psicanálise. Rio de Janeiro: Zahar, 1998.

SAMICO, Fernanda Cabral. Psicanálise no batalhão da polícia militar: uma aposta ética no sujeito. In. Anais do X Simpósio do Programa de Pósgraduação em Psicanálise da UERJ - Psicanálise e saúde: entre o Estado e o sujeito, Rio de Janeiro, 2013.

SOLER, Colette. Los Afectos Lacanianos. Buenos Aires: Letra Viva, 2011. 